BMC JOURNAL OF SCIENTIFIC RESEARCH
A Multidisciplinary Peer Reviewed Research Journal
ISSN: 2594-3421 (Print), 2773-8191 (Online)

\title{
TRANSLANGUAGING IN ENGLISH LANGUAGE TEACHING
}

Padam Prasad Neupane*

padam.neupane@bimc.tu.edu.np

Received: Aug. 4, 2021, Accepted: Dec. 15, 2021

\section{Abstract}

This study explores teachers 'perspectives and practices on translanguaging in English language teaching. Especially, it focuses on how English language teachers perceive and explicate the meaning of translanguaging. The researcher got the primary data from the teachers in different private and public schools in Chitwan. All the respondents were studying in the 4th year of B.Ed major English at Birendra M. Campus Bharatpur; they all were teachers as well. First of all, some survey questions which were related to the study were sent to them via mail and got the written responses by the same means. It happened in such a way because of the lockdown due to the COVID-19. To understand the issue further, I arranged the interview and focus group discussion. I followed the standard process of analysis i.e., coding, categorizing, thematizing, and discussion. Respondents were aware of translanguaging and they took it positively. They agreed that bringing the native languages of every student to classrooms was challenging. They claimed that translanguaging enhances students'creativity and participation in class.

Key Words: Translanguaging, Lockdown, COVID-19, English Language Teaching

\section{Introduction}

Nepalese society is heterogeneous. We cannot imagine the homogenous society here in Nepal. Our societies are linguistically rich and culturally diverse. Nepal is a multiethnic, multilingual as well as multicultural country. This research reflects the same sorts of a diverse society. Whether this sort of environment is favorable for English language teaching or not? In Nepal, the English language is used as a foreign language. We can find bilingual as well as multilingual teaching context.

The study of Translanguaging is a new dimension in the academic field, as the prior research study is merely done on this issue. In Nepal, therefore it gives a new insight to students, researchers, and academicians to focus on the issue of the use of Translanguaging that can be used in the academic field. In the study process, having used the narrative method, this study gives a lived reality, lived experiences, and thick description of the class using Translanguage and the student's perspectives in the use of Translanguaging.

Translanguaging is also a way of teaching or pedagogy, a pedagogy that builds on those fluent language practices that bilingual children have a pedagogy that allows children for example to read in one language and then discuss in another or to read in one language and write in another so way of using all the linguistic resources to make meaning.

\footnotetext{
* Mr. Neupane is Teaching Assistant in Department of Education, English at Birendra Multiple Campus (Tribhuvan University)
} 
"Teaching should be adapted to each pupil's circumstances and needs. It should promote the pupils' further learning and acquisition of knowledge based on pupils' backgrounds, earlier experience, language and knowledge" (Skolverket, 2011). 22

We can imagine very fast using our mother tongue not only this we can express too so we should allow them to express or discuss in that language on which they feel comfortable. It provides bilingual students with positive individual and cultural identities; gives values to the bilingual student's native language (Reyes, 2012). Language brings culture so while learning the second language the students were not familiar with that culture which they are reading so we should allow them to think about their own culture which is similar to that for that again they may discuss in their language.

I have found contradictory views regarding translanguaging. The contradiction is that the supporters of multilingual claimed that the use of mother tongue is quite necessary. So the primary level education should be given in their language so that their creativity will be enhanced. On the other hand, the public is in favor of the international language they wish to see their children learning in the target language from the very beginning. For example, what I have seen in my village of Nawalparasi is that Tharu parents are not willing to learn the Tharu language from their children from the elementary school on the other hand they wish their children should learn English at any cost for that they are ready to pay more; they claim that their children are learning and using their language at their own home so why should they learn at school the same language. To find out the way in this dilemma the study is necessary to carry out so that the way for the Nepalese Teachers for whom English is a foreign language will be clear.

Translanguaging in English language teaching at the School level of Nepal is a burning issue. In this area, we cannot found any research so the big question arises whether Translanguaging facilitates language teaching or not. It facilitates students' creativity or it hinders in this issue we must be clear. In this way, this research will search for the right answer to these questions, so in this English language teaching context, we will have a clear vision to go ahead.

Translanguaging has become a major crux of study for students, researchers, and academicians in Nepal; from this research, the government authorities, development practitioners and professionals, policy-makers, planners, non-government and private organizations can realize, internalize and recognize the usage of application and implication of Translanguaging.

\section{Literature Review}

Our school environment is heterogeneous that is we can find learners with different languages. There is no clear space for the English language in education, although most of the public school has started school in English medium. Birgunj Municipality has declared to run all the public schools in English medium.Stakeholders are focusing on indigenous languages. Nepalese Linguists and researchers are also putting their views in favor of multilingual perspective: So many articles are found in Translanguaging for example: 
Phyak (2018) concluded that Translanguaging pedagogy recognizes students' existing linguistic knowledge and literacy skills to engage them in deeper understanding.

Imposing English as an instructional language for children in Nepali Schools is irrational and as Giri (2011) alleged it is a 'Neo-colonial' ideology.

What is translanguaging and its process is not studied deeply in Nepal up to now. Unknowingly this pedagogy has been in practice in Nepalese school. How the teacher perceive it and their practices as well as attitudes should be studied and the necessary guidance should be provided which will definitely improve the quality of current school teaching.

\section{Method}

"Teachers Perspectives towards translanguaging in English Language Teaching" is my research topic, here the ethnographic method is the base for the study. To get the real glance observation and in-depth interview will be followed under ethnography. To be specific this study gets the data through interview and observation by which qualitative method was followed. In-depth interview was designed but the questions were added to ensure that the relevant data collection. Observation was another tool by which further concept was generated.

Researcher explores the perception of the Teachers' towards Translanguaging. The participants are selected based on the purpose of the study. All the participant's Students are from the same campus as well as from the same level; i.e from B. Ed. Forth year Major English students of Birendra M Campus, Bharatpur, Chitwan. All of them are the teachers of private as well as public schools. The participants are from the different linguistic background; their mother tongue is different for example Nepali, Magar, Newari, and Gurung.

Data Collection Procedures. I have collected the data from the pre-determined respondents by using virtual means. I had sent the survey questionnaires through the mail so I have collected the responses in the same way. After getting responses from this survey still, I was not satisfied with the responses so I took an interview and had invited them on Teams meet and we discussed a lot on this related topic with the help of some questionnaires. For their ease as well as to get a deeper understanding we utilize the mother tongue too.

Data analysis. Survey questions, answers which I had collected through the mail were collected and analyzed. The interviews were recorded. Mails were collected and the researcher. After reading the transcription line by line, coding and marking was followed..

\section{Results}

After analyzing the data the researcher explored the different facets of the topic. Facts were generated through the responses which were taken during interview. Through 
observation as well as the written responses from the mails were analyzed. In this way different aspects of translanguaging, practice and attitudes of the teachers were generated. The following paragraphs highlights the ideas, thoughts, and values shared by the respondents.

Multilingual Situation. Positive attitudes towards multilingualism was found. Various cultures experiences are found as the real resources while exploring the content during the lesson. Multilingual situation brought variety but the challenges were also existed in achieving the objectives of the lesson.

Future working environment. Teachers were found ready to face the multilingual situation. Because of the migration as well as the priority towards local and native variety while teaching English. To cope with the multilingual situation the teachers were expecting further training as well as guidance.

Teacher training program planning. The respondents agreed that while planning teacher training program we should focus to individuals so that we can instruct and plan accordingly. Students' strengths and weakness should be evaluated and treated accordingly. Each students should get the support they need and their experiences, cultures, opportunities for learning. Applying this into students practice is challenging which can be summarized on the basis of respondents.

Teachers' Attitudes towards Translanguaging and mother tongue use. Respondents highlighted the importance of using mother tongue while teaching English. Students' experiences and prior knowledge can be shared in better way through the mother tongue. Balance should be there in the use of target language as well as the mother tongue. Maximum exposure of the target language should be focused according to the respondents. None of them forbidden the use of mother tongue in the classroom for example Respondent A highlighted the importance of using students' native language "When I have to explain a story or something important things for primary level students if they feel quite difficult to understand in English so I use the Nepali language as well". Concerning L1 use in the classroom, participant A observes: On Friday I organize some extracurricular activities at that time I encourage my students to speak in their native language to introduce themselves in front of the class. Respondent A share the different view once as "use of L1 might lead to the confusion during the class which may bring the conflict". Furthermore, regarding translanguaging respondents' response is "translanguaging is good but we as a teacher must be aware all students' native which is quite challenging. Students' creativity and participation during class will be enhanced by translanguaging". Respondents' responsed positively on using students' native language he says, "If they are allowed to share in their native language then they seem quite confident and feel comfortable. Most of the respondents had positive attitudes towards the use of mother tongue. If students are from different mother tongue base then they may face problem during the group work, For assessment purpose target language should be used but for up to discussion their own language can be used. In a case respondents B also raise the issue "If they use their mother tongue instead of link 
language as Nepali language then the problems may arise in communication as well as in group discussion".

\section{Findings and Discussion}

Present study indicates that teachers have positive attitudes towards multilingualism. It is found that there is a general interest in schools for understanding students' various experiences and cultural backgrounds. This study confirms the existence of such interest among teachers. All respondents expressed interest in learning from multilingual students regarding their cultural and linguistic backgrounds. However, from a practical perspective, it could be argued that mother tongue education is not encouraged by authorities since it is not obligatory, it is often an after-school activity, and there is very little time devoted exclusively to mother tongue education.

Some respondents in the present research testified to the fact that they did not feel encouraged to participate in mother tongue education. If students are not encouraged to develop their L1 through mother tongue education, it could be questioned to what extent they are encouraged to develop their linguistic repertoire in other subject classrooms. The importance of developing the students' L1 was acknowledged by all respondents in this study, but not all teachers might acknowledge the interplay between the development of all languages in a student's repertoire and general knowledge acquisition. Some future teachers might likely end up viewing translanguaging and language alternation as a disturbance in the classroom and, consequently, develop negative attitudes towards multilingualism in the school environment. Teachers' perceptions and pre-notions of their future working environment and multilingualism in a school environment can be positively affected by more practical experience and knowledge.

\section{Conclusion}

Lastly, Translanguaging as a pedagogy should be used and practice it carefully with the proper knowledge on the students' background, and their native language and culture too. Teachers were found aware of the concept of translanguaging and automatically without having more knowledge although it is in practice. So, this is the burning issue which needs to be explore more in days to come.

\section{References}

Cenoz, J. (2013). Multilingualism and Education. London: Sage.

Creswell, J. W. (2007).Qualitative inquiry and research design: Choosing among five approaches (2 nd ed.). New Delhi: Sage Publications.

Cummins, J. (2007). Rethinking monolingual instructional strategies in multilingual classroom. Canadian Journal of Applied Linguistics, 10(2), 221-240.

Garcia, O. \& Kleifgen, J. (2010) Educating Emergent Bilinguals: Policies, Programs and Practices for English Language, New York; Teachers College Press 
Giri, R. A. (2011). Languages and language politics: How invisible language politics produces visible results in Nepal. Language Problems \& Language Planning. 16 (1), 32-44.

Harmer, J. (2008). How to teach English. London: Pearson Longman.

Kumar, R. (2006). Research methodology. A step-by step guide for beginners. (2 nd ed.).New Delhi: Dorling Kindersley Pvt.Ltd.

Nunan, D. (2010) Research Methods in Language Learning . Cambridge University Press.

Rai, V. S., Rai, M., Phyak, P., \& Rai, N. (2011). Multilingual education in Nepal: Hearsay and reality. Kathmandu, Nepal: UNESCO

\section{APPENDIX A}

Survey Questionnaires for Written Responses

Teacher's Name

Date

1. Tell me about the English Class.

2. What went well for you/your students when using English/Nepali/Newari/Gurung/Magar?

3. What challenges did you/your students face using English/Nepali/Newari/Gurung/Magar?

4. What do you think of your Teacher? How do you learn?

5. What would you expect differently next time?

6. Tell me about your education.

7. Tell me about your experiences learning or speaking a foreign languages.

8. What do you think good medium of instruction is?

9. WhatchallengesdoyoufaceinimplementingEnglish/Nepali/Newari/Gurung/Magar language as the medium of instructions?

10. How do you meet these challenges?

11. What do you think bringing your own languages into the classroom is good for?

12. What are some challenges you face in doing this?

13. How do you meet these challenges?

14. What do you mean by Multilingualism or Multilanguage Teaching?

15. What is translanguaging? Describe its importance and the use in English language teaching.

\section{APPENDIX B}

Questionnaires for the Interview

1. How long have you been teaching (Years)?

2. What is your Native Language?
a. Nepali
b. Magar
c. Gurung 


\section{d. Newari}

3. Do you work in a bilingual/dual language school, or a mainstream (Englishspeaking) school?

4. How many total students do you teach in a day?

5. How many of your students are native Magar/ Gurung/Newari speakers?

6. What is their primary language of instruction in your class?
a. Nepali
b. Magar
c. Gurung
d. Newari

7. In your own words, please describe in which situations using the students' native language is beneficial, and in which situations is it detrimental?

8. Is there any additional information that you would like to share about your perception or use (either by the teacher or by the student) of the use of students' native language in the classroom?

9. How do English language teachers perceive and explicate the meaning of the Translanguaging? 